\title{
Research on the Influencing Factors and Evaluation System of Enterprise Strategy Adaptation Ability
}

\author{
Haixu Song ${ }^{1, a,}$, Xiaofeng Zhang ${ }^{1, b}$ and Xiaodong $\mathrm{Li}^{1, \mathrm{c}}$ \\ ${ }^{1}$ State Grid Energy Research Institute Co., Ltd, SGCC Administrative Area, Future Science and \\ Technology Park North Area, Beqijia Town, Changping, Beiqijia, P. R. China \\ ashxstudent@126.com, bzhangxiaofeng@sgeri.sgcc.com.cn, 'lixiaodong@sgeri.sgcc.com.cn \\ ${ }^{*}$ Corresponding author
}

Keywords: Enterprise strategy, Strategy adaptation ability, Evaluation system

\begin{abstract}
Based on the research results at home and abroad, this paper studies the influencing factors and evaluation system of Strategy Adaptation Ability. The study considers that enterprises need to grasp the changes of the external environment accurately and make correct adjustments timely with the uncertainty of the external environment. The key is to improve four ability for four aspects: environmental awareness ability, situation judgment ability, strategic decision-making ability and organizational adaptability. This paper provides theoretical support and application tools for enterprises to improve their strategic management level and enhance their sustainable development capabilities.
\end{abstract}

\section{Introduction}

With the development of industrial revolution and technological revolution, the future development situation is changing increasingly. The uncertainty of business environment is becoming stronger. The static strategy can no longer meet the needs of enterprise development. It needs that the strategy can respond to environment changes quickly in order to seize strategic opportunities and achieve rapid development. So it is of great significance to improve strategy adaptation ability.

The analysis and enterprise strategy adaptation ability has always been the focus of academic circles. From the perspective of contingency theory, Miles and Snow (1994) considered that successful companies are organizations that match the environment organically. From the perspective of population ecology, Hannan and Freeman (1977) believed that the environment defines the strategies and paths that an organization must follow. From the perspective of strategic choice theory, Schindehutte and Morris (2001) argued that environmental conditions couldn't be considered as a direct source of differences in organizational structure, and managers have the right of judgment and higher decision-making. From the perspective of cognition, Chen and Chen (2007) believed that the strategic adjustment of the senior management team consisted of the ability to target and the ability to coordinate. The former is determined by heterogeneous cognitive ability, and the latter is influenced by the level of recognition of strategic adjustment programs by executive team members. Wei and Chen (2011) found that the external environment, internal resources and capabilities, corporate concept and innovation, corporate strategy, core competitiveness and sustainable competitive advantage are the main factors that affected the enterprise strategy adaptation ability.

In general, the current research on enterprise strategy adaptation ability has achieved rich results, but most of them are qualitative studies, and quantitative description and evaluation of strategy adaptation ability are few. In view of this, based on the existing research results, this paper studies the influencing factors and evaluation of strategy adaptation ability, and provides theoretical support and application tools for enterprises, to improve their strategic management level and enhance their sustainable development ability. 


\section{Analysis of factors affecting enterprise strategy adaptation ability}

Strategy Adaptation Ability is the ability of an enterprise to adjust and adapt its strategy in a highly complex and uncertain environment timely. It is the foundation for a company to achieve sustainable development and achieve long-term success. At present, enterprises are facing an increasingly complex external environment. Industrial revolution and technological change are rapidly changing the environment of enterprises. Enterprises must be able to grasp the changing environment and make strategic adjustments in a timely manner to achieve a sustainable competitive advantage. The size of corporate strategic adjustment depends on two levels: one is to grasp the environment accurately, and the other is to make correct adjustments. Specifically, its influencing factors include environment perception ability, situation judgment ability, strategic decision-making ability, and organizational adaptability.

(1) Environment perception ability

Environment perception ability is the ability of an enterprise to capture and acquire information about changes in the external environment by means of internal organizational organizations. Environment perception is a process of information search. Information search is a generator of organizational information. It not only searches for customer and competitor information, but also searches for information from other stakeholders. For enterprises, being able to grasp environmental changes quickly and accurately, is a prerequisite for companies to make correct strategic adjustments. Environment perception includes both the awareness and mechanism of the enterprise's access to information, as well as the content and methods of the enterprise's access to information, such as the attitude, frequency, scope, process, and major departments and personnel involved in the tracking and collection of environment information.

(2) Situation judgment ability

Situation judgment ability is the ability of an enterprise to process, analyze, and judge information effectively based on environment change. The situation research is a process of information handing, such as judging the importance of information, screening and processing information, analyzing the future trends and the impact on enterprises in combination with the characteristics of enterprises. Situation judgment is the basis for enterprises to make strategic adjustments. What strategic choice a company makes depends on how it predict and recognize the future situation. The ability to judge the situation includes the scientificity and effectiveness of information processing, such as the frequency, content, method of situation analysis, the degree of participation about key leaders, the methodological tools used, and so on.

(3) Strategic decision-making ability

Strategic decision-making ability is the ability of an enterprise to optimize and adjust its strategy according to environmental changes in a timely and appropriate manner. From the perspective of information flow, strategic decision-making is a process of information utilization. On the one hand, strategic decision-making must be able to adapt to changes in the external environment and conform to the general trend of the situation; on the other hand, strategic decision-making must be consistent with the strength of the enterprise, expected to bring benefits to the enterprise. Specifically, the strategic decision-making ability of an enterprise includes the following aspects: whether the enterprise makes decision adjustment according to environment changes, the matching of enterprise decision-making adjustment and environment change, the matching of strategy adjustment and the actual situation of the company, the target task of the adjustment strategy, and the prevention and circumvention of related risks.

(4) Organizational adaptability

Organizational adaptability is the ability of an enterprise to adjust its own structure and behavior according to environment changes and strategic changes. Organizational adaptation is mainly reflected in the process of strategy implementation. And it is the process of continuous selection, learning and growth of the organization. Organizational adaptation is also a feedback process. When environment changes cause internal changes in the organizational system, the system will also react to the environment according to its own understanding, causing new changes in the entire ecology. Organizational adaptability can include: whether the organizational structure is adjusted in time, 
whether the adjusted organizational structure can meet new needs, whether the department collaboration is smooth, and the employee's understanding and acceptance of the new strategy.

In general, enterprise strategy adaptation ability is a process of a series of reactions and actions on changes in the external environment around strategy analysis, strategy formulation, and strategy execution.

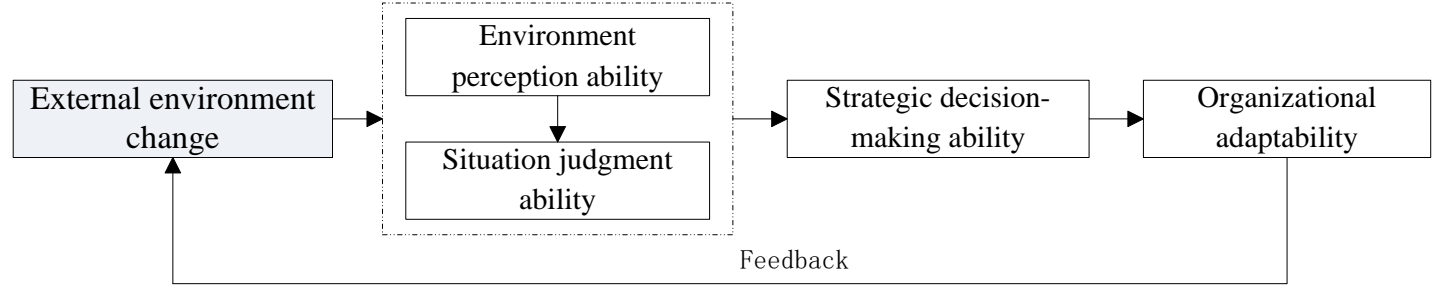

Fig. 1. Influencing factors of enterprise strategy adaptation ability

\section{Evaluation system construction of enterprise strategy adaptation ability}

\subsection{Construction principle}

The enterprise strategy adaptation ability evaluation system consists of a series of indicators with different dimensions, and it is an organic whole that can reflects the strategy adaptation ability comprehensively. In order to improve the scientific and rationality of the evaluation system, it should be followed some principles:

(1) Systematic principles. The systemic principle refers to a comprehensive grasp and analysis of strategy adaptation ability as a whole. It is necessary to consider the external environment fully, so that the indicator system is comprehensive and not overlapping mutually.

(2) The principle of importance. There are many factors that affect the strategy adaptation ability of enterprises. However, the indicator system cannot cover all the indicators, so it should be selected the ones important and representative.

(3) The principle of simplicity. For the evaluation system, it is necessary to be simple, practical. It will reduce the usability and practicability if the evaluation system is too complicated. But simplicity doesn't mean that the content is simple, and it means that the design and description of the indicator should be concise and clear.

\subsection{Evaluation system construction}

According to the factors affecting the strategy adaptation ability, the paper analyzes the content of each dimension, to form the evaluation index system.

Environment perception ability includes the timeliness of information acquisition, the comprehensiveness of information content, the effectiveness of information content, and the normative nature of tracking management. Among them, the timeliness of information acquisition refers to whether the enterprise can obtain relevant information about changes in the external environment timely. The comprehensiveness of information content refers to whether the environmental change information collected by enterprises is comprehensive. The effectiveness of information content refers to whether the information tracked by the enterprise is closely related to the business operation, and is helpful to the decision-making. The normative nature of tracking management refers to whether the process of collecting and tracking information is regulated, and whether the responsible personnel are professional.

Situation judgment ability includes the accuracy of situation judgement, the scientific nature of situation judgement, and the depth of situation judgement. Among them, the accuracy of the situation judgment refers to whether the enterprise's judgment on the situation is accurate and whether it can grasp the future development trend. The scientific nature of situation judgement is whether the methods and tools used in the judgment are scientific, advanced and objective. The depth of situation judgment refers to whether it has grasped the fundamental elements and key impacts of the changes in the situation. 
Strategic decision-making ability includes the timeliness of strategic adjustment, the correctness of adjustment direction, the clarity of adjustment objectives, the operability of adjustment strategy, and the prevention of strategic risks. Among them, the timeliness of strategic adjustment refers to whether the enterprise can make adjustments to the strategy timely according to environmental changes. The correctness of adjustment direction refers to whether the direction of corporate strategic adjustment is correct and whether it adapts to changes in the environment. The clarity of adjustment objectives refers to whether the objectives are clear and easy to understand. The operability of adjustment strategy refers to whether the adjusted strategy conforms to the actual situation of the enterprise, whether it can perform task decomposition, and whether it is operable. Strategic risk prevention refers to whether the enterprise analyzes and guards the relevant risks fully when it adjusts the strategy.

Organizational adaptability includes the adaptability of organizational structure, the depth of employee understanding, and the strength of employee learning ability. Among them, the adaptability of organizational structure refers to whether the organizational structure has been adjusted accordingly, and whether it can meet the new requirements brought about by strategic changes. The depth of employee understanding means whether employees can understand the connotation of the adjusted strategy deeply and implement it correctly. The strength of employee learning ability refers to whether employees have the corresponding concepts, qualities and professional capabilities to meet the new requirements brought about by strategic changes.

Table 1. Enterprise strategy adaptation ability index system

\begin{tabular}{|c|c|c|}
\hline Evaluation dimension & sub-dimension & main contents \\
\hline \multirow{4}{*}{$\begin{array}{l}\text { Environment perception } \\
\text { ability }\end{array}$} & $\begin{array}{l}\text { Timeliness of information } \\
\text { acquisition }\end{array}$ & $\begin{array}{l}\text { Whether the enterprise can obtain relevant information } \\
\text { about changes in the external environment timely }\end{array}$ \\
\hline & $\begin{array}{l}\text { Comprehensiveness of } \\
\text { information content }\end{array}$ & $\begin{array}{l}\text { Whether the environmental change information collected by } \\
\text { enterprises is comprehensive }\end{array}$ \\
\hline & $\begin{array}{l}\text { Effectiveness of information } \\
\text { content }\end{array}$ & $\begin{array}{l}\text { Whether the information tracked by the enterprise is closely } \\
\text { related to the business operation, and is helpful to the } \\
\text { decision-making }\end{array}$ \\
\hline & $\begin{array}{l}\text { Normative nature of tracking } \\
\text { management }\end{array}$ & $\begin{array}{c}\text { Whether the process of collecting and tracking information } \\
\text { is regulated, and whether the responsible personnel are } \\
\text { professional }\end{array}$ \\
\hline \multirow{3}{*}{$\begin{array}{l}\text { Situation judgment } \\
\text { ability }\end{array}$} & Accuracy of situation judgment & $\begin{array}{c}\text { Whether the enterprise's judgment on the situation is } \\
\text { accurate and whether it can grasp the future development } \\
\text { trend }\end{array}$ \\
\hline & $\begin{array}{l}\text { The scientific nature of situation } \\
\text { judgment }\end{array}$ & $\begin{array}{l}\text { Whether the methods and tools used in the judgment are } \\
\text { scientific, advanced and objective }\end{array}$ \\
\hline & The depth of situation judgment & $\begin{array}{l}\text { Whether the enterprise has grasped the fundamental } \\
\text { elements and key impacts of the changes in the situation }\end{array}$ \\
\hline \multirow{5}{*}{$\begin{array}{c}\text { Strategic } \\
\text { decision-making ability }\end{array}$} & $\begin{array}{c}\text { Timeliness of strategic } \\
\text { adjustment }\end{array}$ & $\begin{array}{l}\text { Whether the enterprise can make adjustments to the strategy } \\
\text { timely according to environmental changes }\end{array}$ \\
\hline & $\begin{array}{l}\text { Correctness of adjustment } \\
\text { direction } \\
\end{array}$ & $\begin{array}{l}\text { Whether the direction of corporate strategic adjustment is } \\
\text { correct and whether it adapts to changes in the environment }\end{array}$ \\
\hline & $\begin{array}{l}\text { Clarity of the adjustment } \\
\text { objectives }\end{array}$ & Whether the objectives are clear and easy to understand \\
\hline & $\begin{array}{l}\text { Operability of adjustment } \\
\text { strategy }\end{array}$ & $\begin{array}{l}\text { Whether the adjusted strategy conforms to the actual } \\
\text { situation of the enterprise, whether it can perform task } \\
\text { decomposition, and whether it is operable }\end{array}$ \\
\hline & Prevention of strategic risks & $\begin{array}{l}\text { Whether the enterprise analyzes and guards the relevant } \\
\text { risks fully when it adjusts the strategy }\end{array}$ \\
\hline \multirow{3}{*}{$\begin{array}{l}\text { Organizational } \\
\text { adaptability }\end{array}$} & $\begin{array}{l}\text { Adaptability of organizational } \\
\text { structure }\end{array}$ & $\begin{array}{c}\text { Whether the organizational structure has been adjusted } \\
\text { accordingly, and whether it can meet the new requirements } \\
\text { brought about by strategic changes }\end{array}$ \\
\hline & $\begin{array}{l}\text { Depth of employee } \\
\text { understanding }\end{array}$ & $\begin{array}{l}\text { Whether employees can understand the connotation of the } \\
\text { adjusted strategy deeply and implement it correctly }\end{array}$ \\
\hline & $\begin{array}{l}\text { Strength of employee learning } \\
\text { ability }\end{array}$ & $\begin{array}{l}\text { Whether employees have the corresponding concepts, } \\
\text { qualities and professional capabilities to meet the new } \\
\text { requirements brought about by strategic changes }\end{array}$ \\
\hline
\end{tabular}




\subsection{Evaluation steps and methods}

Through the above analysis, it is found that the evaluation indicators of strategy adaptation ability are mainly qualitative indicators. Considering that qualitative indicators are difficult to quantify and standardize, the combination of expert scoring method and level description method is adopted. Firstly, these qualitative indicators are quantitatively transformed, then the weights of each index are determined, and finally strategy adaptation ability is evaluated. Specific steps are as follows:

(1) Select experts

In combination with the content of strategy adaptation ability, it selects a certain number of experts according to the principle of multi-field and multi-institutional. The experts should cover a wide range of professional fields such as economics, management. And it also should cover many institutions such as government agencies, universities and research institutes, to ensure the comprehensiveness and objectivity of evaluation.

(2) Determine the evaluation level and basis

Design the likert table, and clarify the standards of each level according to 1-5 points. The higher the score, the stronger the ability of the company in the process of strategy adjustment.

(3) Single indicator evaluation

First of all, the experts are consulted anonymously, and each expert judges the strategy adaptation ability and assigns points. Then, the experts' opinions are analyzed and summarized, and the statistical results are fed back to the experts. The experts correct their own opinions based on the feedback results. Finally, the final analysis conclusions were formed and the scores for each sub-dimension were obtained after several rounds of anonymous consultation and feedback.

(4) Comprehensive evaluation

Firstly, the paper used the analytic hierarchy process to set the weights of each dimension and each indicator. And then the overall score of the strategy adaptation ability is calculated according to the weight and score of the sub-dimension.

\section{Conclusion}

Based on the research results at home and abroad, this paper studies the influencing factors and evaluation system of Strategy Adaptation Ability. The study considers that enterprises need to grasp the changes of the external environment accurately and make correct adjustments timely with the uncertainty of the external environment. The key is to improve four ability for four aspects: environmental awareness ability, situation judgment ability, strategic decision-making ability and organizational adaptability. This paper provides theoretical support and application tools for enterprises to improve their strategic management level and enhance their sustainable development capabilities.

\section{References}

[1] Sydow and Staber, Organizational adaptive capacity. Journal of Management Inquiry: A Structuratial Perspective, vol. 11(4), pp. 408, 2002.

[2] Venkatraman and C. C. John. Exploring the concept of "Fit" in strategic management. Academy of ManagementReviews, vol. 9(3), pp. 513- 523, 1984.

[3] E. Helfat and S. Raubitschek. Product sequencing: co-evolution of knowledge, capabilities and products. Strategic Management Journal, Special Issue: The Evolution of Firm Capabilities, vol. 10, pp. 961- 970, 2000.

[4] G. P. Xiang and Y. Sheng. Corporate strategic resilience and corporate strategic change model: an investigation from the perspective of knowledge. Science and Technology Progress and Countermeasures, vol. 7, pp. 75-77, 2005. 
[5] X. B. Zhao and Z. Z. Fei. Non-equilibrium analysis: a new perspective of enterprise environment research. Economics and Management Research, vol. 4, pp.53-56, 2004. 